\title{
PENDUGAAN STOK IKAN KERAPU (GROUPER) DI PERAIRAN SELAT MAKASSAR SULAWESI SELATAN PERIODE TAHUN 1999 - 2007
}

\author{
Rochmady* dan Susiana** \\ "Staf Pengajar STPertanian Wuna, Raha, email : kampo.mokesano@gmail.com \\ **Staf Pengajar Universitas Maritim Raja Ali Haji (UMRAH), Kepri, email : -
}

\begin{abstract}
ABSTRAK
Penelitian bertujuan untuk menganalisis tingkat potensi maksimum lestari (MSY) ikan kerapu di perairan Selat Makassar, Sulawesi Selatan, meliputi data produksi dan jumlah trip alat tangkap yang digunakan mulai tahun 1998-2007. Data hasil tangkapan ikan menurut jenis alat tangkap dan jenis ikan dilakukan standarisasi alat tangkap melalui pendekatan fishing power index (FPI) terhadap seluruh jenis alat tangkap. Selanjutnya dilakukan estimasi potensi lestari (MSY) menggunakan model Schaefer (1954) dan Fox (1970). Hasil penelitian menunjukkan penangkapan ikan kerapu di perairan Sulawesi Selatan menggunakan alat tangkap berupa payang, dogol, pukat pantai, pukat cincin, jaring insang hanyut, jaring insang tetap, trammel net, bagan perahu, bagan tancap, rawai tetap, pancing yang lain, sero, bubu dan perangkap yang lainnya. Dengan model Schaefer (1954) diketahui upaya tangkap maksimum $\left(F_{\text {opt }}\right)$ sebesar 171984.6149 trip per tahun, hasil tangkapan maksimum lestari (MSY) sebesar 85992.30745 ton per tahun. Tingkat pemanfaatan pada tahun 2007 sebesar 583.5 ton dengan tingkat upaya penangkapan sebesar 73355 trip. Model Fox (1970) diketahui upaya tangkap maksimum lestari $\left(F_{\text {opt }}\right)$ sebesar 124984 trip per tahun, hasil tangkapan maksimum lestari (MSY) sebesar 1551.927677 ton per tahun. Berdasarkan kedua model estimasi tersebut diketahui setiap penambahan satu satuan unit upaya penangkapan (trip) akan berdampak pada pengurangan nilai hasil produksi ikan kerapu.
\end{abstract}

Kata Kunci: Pendugaan Stok, Ikan Kerapu, Selat Makassar.

\section{PENDAHULUAN}

Ikan kerapu sunu merupakan salah satu komoditas ekspor yang diminati oleh masyarakat luar maupun dalam negeri. Oleh karena itu, kegiatan penangkapannya semakin hari semakin meningkat. Peningkatan aktivitas penangkapan ini, mengakibatkan populasi ikan kerapu sunu di alam semakin menurun dan bahkan dikhawatirkan populasi ikan tersebut akan mengalami kepunahan. Oleh karena itu, diperlukan suatu upaya pengelolaan dan produksi alternatif selain kegiatan penangkapan di alam melalui usaha budidaya dan pengelolaan kegiatan penangkapan di alam itu sendiri. Peningkatan aktivitas penangkapan disebabkan banyak faktor, antara lain karena nilai gizi ikan kerapu sunu yang tinggi, sehingga ikan kerapu sunu juga memiliki harga jual yang relatif cukup tinggi.

Dua jenis kerapu sunu yang berharga jual tinggi dan terdapat di Indonesia yaitu Plectropomus leopardus (leopard corraltrout) dan P. maculatus (barred cheek corral trout) (Gambar 1). Harga jual jenis leopardus hidup dilaporkan mencapai sekitar US\$30/kg pada tahun 2006 (Swadaya, 2008).

Kawasan Asia Pasifik merupakan tempat paling nyaman bagi ikan karang. Tahun 1997, kawasan ini memasok 90 persen total produksi ikan kerapu dunia atau sekitar 15.000 ton. Cina adalah merupakan produser terbesar dunia dengan suplai sekitar 8.000 ton ikan kerapu per 
tahun. Sementara itu, Indonesia berada di tempat kedua dengan pertumbuhan produksi 14,7 persen per tahun. Untuk memenuhi permintaan pasar dunia, nelayan Indonesia umumnya masih menangkap dari alam. Tingginya permintaan ikan kerapu hidup untuk konsumsi telah menjadi salah satu pemicu nelayan menangkap ikan kerapu dengan menggunakan berbagai macam cara, agar ikan-ikan karang itu keluar dari sarangnya. Cara-cara tersebut termasuk di dalamnya penggunaan alat dan cara yang merusak lingkungan yang antara lain racun potasium atau sianida dan bom. Sangat jelas bahwa aktivitas penangkapan dengan menggunakan cara tersebut telah merusak habitat maupun lingkungan sekitar, oleh karena bersamaan dengan itu ribuan ikan kecil lain yang tidak menjadi target penangkapan akan mati dan terumbu karang yang menjadi habitat ikan mengalami kehancuran. Menurut World Wild Fund for Nature (WWF), melaporkan bahwa kerusakan terumbu karang di Indonesia relatif sangat tinggi, mencapai 42 persen dengan kondisi yang rusak parah (Anonim, 2010).

Hal lain dari kecenderungan peningkatan aktivitas penangkapan ikan kerapu sunu adalah penangkapan berlebih sebagai dampak yang tidak terhindarkan. Di perairan Indonesia, menurut data dari Departemen Kelautan dan Perikanan (DKP), dilaporkan bahwa pemanfaatan ikan karang, termasuk di dalamnya jenis kerapu, memang sudah berada pada posisi di atas 100 persen. Dari potensi 145 ribu ton per tahun, yang ditangkap telah mencapai 156 ribu ton. Hal ini berarti bahwa ikan kerapu telah berada pada kondisi penangkapan lebih. Menurut Komisi Nasional Pengkajian Sumberdaya Perikanan Laut, lokasi yang telah mengalami gejala tangkap lebih untuk ikan karang meliputi perairan Laut Jawa, Selat Makassar, Laut Flores, Laut Banda, Laut Sulawesi, perairan di selatan Indonesia atau Samudra Hindia, dan di utara atau Samudra Pasifik. Dilihat dari jumlahnya, potensi kelompok ikan karang di perairan Indonesia memang tidak tergolong melimpah dibandingkan dengan ikan pelagis besar $(1,1$ juta ton per tahun), ikan pelagis kecil $(3,6$ juta ton per tahun), dan ikan demersal (1,3 juta ton per tahun). Tetapi, pemanfaatan ketiga jenis itu masih 50-80 persen (Kompas, 2003).

Sumberdaya ikan perlu dikelola dengan baik karena merupakan sumberdaya hayati yang dapat diperbaharui (renewable), namun dapat mengalami tangkap lebih (overfishing), deplesi ataupun kepunahan. Dengan demikian, mengelola suatu sumberdaya ikan dengan cara benar dan tepat menjadi suatu keharusan. Dalam pemanfaatan sumberdaya ikan di laut, salah satu permasalahan utama adalah berapa banyak ikan yang dapat ditangkap tanpa mengganggu keberadaan stok, atau bagaimana panen biomassa ikan dapat dimaksimalkan tanpa mengganggu prospek eksploitasi di masa mendatang. Salah satu cara pendekatan dalam pengelolaan sumberdaya ikan ialah melalui pemodelan (Kekenusa, 2007).

Metode yang dapat digunakan untuk menentukan estimasi hasil tangkapan maksimum lestari (MSY) yaitu melalui pendekatan model produksi surplus. Model tersebut berkaitan dengan suatu stok secara keseluruhan, upaya total dan hasil tangkapan total yang diperoleh dari stok, tanpa memasukkan secara rinci beberapa hal seperti parameter pertumbuhan dan mortalitas atau pengaruh ukuran mata jaring terhadap umur ikan yang tertangkap, dan lain-lain.

\subsection{Tujuan dan Kegunaan}

Tujuan penelitian untuk menganalisis tingkat produksi lestari atau Maksimum Sustainable Yield (MSY) ikan kerapu (grouper) di perairan Selat Makassar Sulawesi Selatan meliputi data produksi dan jumlah trip alat tangkap yang digunakan dari setiap tahunnya (1998-2007).

Dengan mengetahui produksi maksimum lestari atau Maksimum Sustainable Yield (MSY) dan upaya optimum (Foptimum), maka penelitian ini dapat dijadikan sebagai bahan informasi untuk menganalisa keberadaan ikan kerapu di perairan Selat Makassar Sulawesi Selatan sehingga dapat memberikan informasi alternatif kebijakan pengelolaan sumberdaya ikan, khususnya ikan kerapu. 

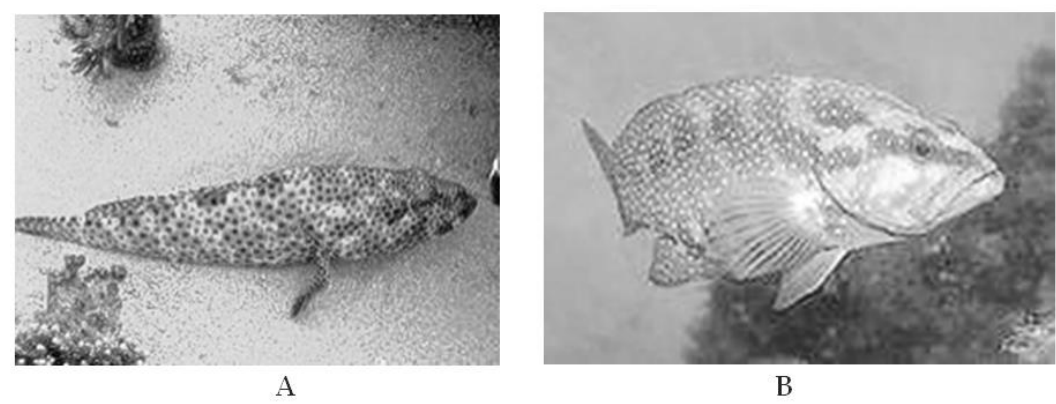

Gambar 1. Morfologi Ikan Kerapu (grouper) (A, Kerapu Kayu; B, Kerapu Sunu)

\section{METODE PENELITIAN}

\subsection{Waktu dan Tempat}

Penelitian pendugaan stok ikan kerapu (grouper) meliputi Potensi Maksimum Lestari (MSY) dan Upaya Optimum (Foptimum) dilakukan pada bulan Mei 2010 di perairan Selat Makassar Sulawesi Selatan meliputi Kota Makassar, Kabupaten Maros, Kabupaten Pangkajene dan Kepulauan (Pangkep), Kabupaten Barru, Kota Pare-Pare dan Kabupaten Pinrang.

Analisa data dilakukan pada Laboratorium Komputer Pascasarjana Universitas Hasanuddin. Data yang digunakan diperoleh dari Dinas Kelautan dan Perikanan Provinsi Sulawesi Selatan.

\subsection{Metode Pengambilan Data}

Data primer diperoleh dari Dinas Kelautan dan Perikanan Provinsi Sulawesi Selatan yang meliputi data hasil tangkapan dan data trip setiap alat tangkap yang digunakan menangkap ikan kerapu (grouper) dari total kabupaten yang ada di Selat Makassar Sulawesi Selatan mulai dari tahun 1998-2007.

Pengolahan data primer dilakukan di Laboratorium Komputer Pascasarjana Universitas Hasanuddin dengan menginput dan mengolah data melalui program Microsoft Excel.

\subsection{Analisa Data}

\subsubsection{Standarisasi Alat Tangkap}

Unit effort (upaya) sejumlah armada penangkapan ikan dengan alat tangkap dan waktu tertentu dikonversi ke dalam satuan "boat-days" atau trip. Pertimbangan yang digunakan adalah :

1. Respon stock terhadap alat tangkap standar akan menentukan status sumberdaya selanjutnya berdampak pada status perikanan alat tangkap lain,

2. Total hasil tangkap ikan per unit effort alat tangkap standar lebih dominan dibanding alat tangkap lain, dan

3. Daerah penangkapan alat tangkap standar meliputi dan atau berhubungan dengan daerah penangkapan alat tangkap lain.

Unit effort sejumlah armada penangkapan ikan dengan alat tangkap dan waktu tertentu dikonversi ke dalam satuan "boat-days" atau trip. Prosedur standarisasi alat tangkap ke dalam satuan baku unit alat tangkap standar, dapat dilakukan sebagai berikut :

1. Alat tangkap standar yang digunakan mempunyai CPUE terbesar dan memiliki nilai faktor daya tangkap (fishing power index, FPI) sama dengan 1. Nilai FPI dapat diperoleh melalui persamaan (Gulland, 1983):

$$
\begin{aligned}
& \text { CPUE }_{r}=\frac{\text { Catch }_{r}}{\text { Effort }_{r}}, \\
& \text { CPUE }_{s}=\frac{\text { Catch }_{s}}{\text { Effort }_{s}}, \\
& \text { FPI }=\frac{\text { CPUE }_{r}}{\text { CPUE }_{s}}, \ldots . .
\end{aligned}
$$

dimana :

CPUEr = total hasil tangkapan (catch) per upaya tangkap (effort) dari alat tangkap $r$ yang akan distandarisasi (ton/trip).

CPUEs = total hasil tangkapan (catch) per upaya tangkap (effort) dari alat tangkap $s$ yang dijadikan standar (ton/trip).

FPI = fishing power index dari alat tangkap i (yang distandarisasi dan alat tangkap standar) 
2. Nilai FPI digunakan untuk menghitung total upaya standar, yakni :

$E=\sum_{i=1}^{l} F_{P I} E_{i}$

dimana :

$E$ = total effort atau jumlah upaya tangkap dari alat tangkap yang distandarisasi dan alat tangkap standar (trip)

Ei $=$ effort dari alat tangkap yang distandarisasi dan alat tangkap standar (trip)

\subsubsection{Estimasi Potensi Lestari}

Estimasi potensi sumberdaya perikanan tangkap didasarkan atas jumlah hasil tangkapan ikan yang didaratkan pada suatu wilayah dan variasi alat tangkap per trip. Prosedur estimasi menurut Sparre dan Venema (1999) dilakukan dengan cara:

1. Menghitung hasil tangkapan per upaya tangkap (CPUE), melalui persamaan:

$$
\mathrm{CPUE}_{\mathrm{n}}=\frac{\mathrm{Catch}_{\mathrm{n}}}{\mathrm{E}_{\mathrm{n}}}, \mathrm{n}=1,2,3, \ldots \mathrm{M}
$$

dimana :

CPUEn = total hasil tangkapan per upaya penangkapan yang telah distandarisasi dalam tahun $\mathbf{n}$ (ton/trip)

Catchn $=$ total hasil tangkapan dari seluruh alat dalam tahun $\mathbf{n}$ (ton)

En = total effort atau jumlah upaya tangkap dari alat tangkap yang distandarisasi dengan alat tangkap standar dalam tahun $\mathrm{n}$ (trip).

2. Melakukan estimasi parameter alat tangkap standar dengan menggunakan model Schaefer berikut :

$$
\mathrm{CPUEn}_{n}=\alpha-\beta \mathrm{En}_{\mathrm{n}}
$$

Atau

$\operatorname{Catch}_{n}=\alpha E_{n}-\beta E_{n}^{2}$

dimana :

CPUEn = total hasil tangkapan per upaya setelah distandarisasi pada tahun $n$ (ton/trip)

En $=$ total effort standar pada tahun $n$ (trip/tahun)

$\alpha$ dan $\beta=$ konstanta dan koefisien parameter dari model Schaefer
Persamaan (4.28) dihitung dengan menggunakan metode regresi linear sederhana (Ordinary Least Square, OLS).

3. Melakukan estimasi effort optimum pada kondisi keseimbangan (equilibrium state), digunakan persamaan :

$E_{o p t i}=1 / 2(\alpha / \beta)$

4. Melakukan estimasi Maximum Sustainable Yield (MSY) sebagai indikator potensi sumberdaya perikanan tangkap yang berkelanjutan (lestari) melalui persamaan :

$\operatorname{MSY}=1 / 4(\alpha / \beta)$

Nilai effort optimum dan MSY yang diperoleh melalui persamaan (3) dan (4) selanjutnya dimasukkan sebagai kendala tujuan dalam model ekonomi sumberdaya perikanan tangkap (model dasar LGP). Dengan demikian, secara biologi pengelolaan perikanan menunjukkan optimalisasi pemanfaatan sumberdaya perikanan tangkap yang berkelanjutan.

\section{HASIL DAN PEMBAHASAN}

Berdasarkan analisis data yang telah dilakukan, maka didapatkan hasil, sebagaimana yang terdapat pada Tabel 1 .

Penangkapan ikan kerapu di perairan Sulawesi Selatan ditemukan menggunakan beberapa jenis alat tangkap seperti payang, dogol (beach seine), pukat pantai, pukat cincin (purse seine), jaring insang hanyut, jaring insang tetap, trammel net, bagan perahu, bagan tancap, rawai tetap, pancing yang lain, sero, bubu dan perangkap yang lain.

Produksi Surplus yang digunakan untuk menelaah hasil tangkapan ikan kerapu di perairan Selat Makassar Sulawesi Selatan dengan menggunakan model Schaefer (1954) dan model Fox (1970).

Upaya tangkap maksimum per tahun dengan pendekatan model Scahafer di perairan Selat Makassar Sulawesi Selatan adalah 171984.6149 trip. Hasil tangkapan maksimum lestarinya (MSY) adalah 85992.30745 ton. Tingkat pemanfaatan untuk tahun 2007 sebesar 583.5 ton dengan tingkat pengupayaan sebesar 73355 trip. (Gambar 2). 
Tabel 1. Catch, Effort standar, CPUE, dan Ln CPUE ikan kerapu di Perairan Selat Makassar Sulawesi Selatan tahun 1999 - 2007 berdasarkan metode Scaefer dan Fox.

\begin{tabular}{rcrrr}
\hline Tahun & $\begin{array}{c}\text { Catch } \\
\text { (Ton) }\end{array}$ & Effort Standar (Trip) & \multicolumn{1}{c}{ CPUE } & In CPUE \\
\hline 1999 & 271.9 & 306214 & 0.00089 & -7.02661 \\
2000 & 267.7 & 331284 & 0.000808 & -7.12086 \\
2001 & 330.3 & 347119 & 0.000952 & -6.95742 \\
2002 & 328.4 & 216901 & 0.001514 & -6.49296 \\
2003 & 392.1 & 294985 & 0.001329 & -6.62316 \\
2004 & 497.0 & 261994 & 0.001897 & -6.26749 \\
2005 & 525.0 & 189739 & 0.002767 & -5.89001 \\
2006 & 444.3 & 215362 & 0.002063 & -6.18358 \\
2007 & 583.5 & 73355 & 0.007955 & -4.83401 \\
\hline
\end{tabular}

MSY dan Fopt Pendekatan Schaefer

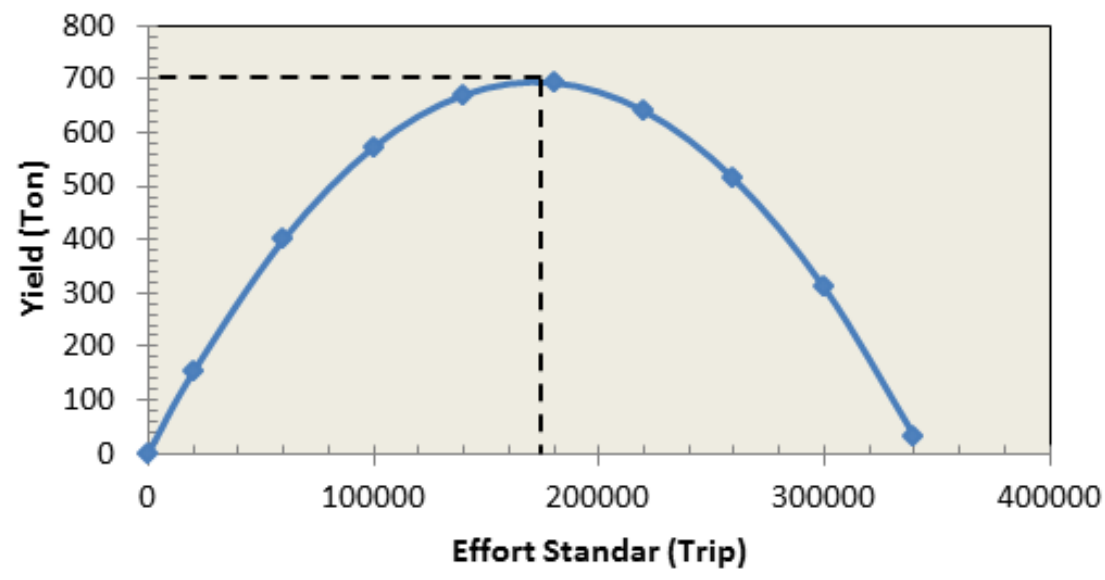

Gambar 2. Kurva MSY berdasarkan pendekatan model Schaefer Ikan Kerapu di Perairan Selat Makassar Sulawesi Selatan Tahun 1999-2007.

Gambar 2 menunjukkan bahwa jika faktor di luar effort diabaikan, maka akibat penambahan effort secara terus-menerus, hasil tangkapan akan mengalami penurunan. Ini berarti bahwa pada effort di atas 171984.6149 trip per tahun, jika melewati Fopt maka dianggap usaha penangkapan tersebut merugi karena biaya operasional lebih besar dari biaya penangkapan.

Cara paling sederhana untuk mengekspresikan hasil tangkapan per unit upaya, $Y / f$, sebagai fungsi daripada upaya, $f$ adalah model linier yang disarankan oleh Schaefer (1954):

$$
\frac{\mathbf{Y}(\mathbf{i})}{\mathbf{F}(\mathbf{i})}=\mathbf{a}+\mathbf{b}^{*} \mathbf{f}(\mathbf{i}), \quad \text { bila } \mathbf{f}(\mathbf{i}) \leq \frac{-\mathbf{a}}{\mathbf{b}}
$$

Selain model Schaefer (1954), dapat digunakan model alternatif yang diperkenalkan oleh Fox (1970). Dengan pendekatan model Fox, upaya tangkap maksimum di perairan Selat Makassar Sulawesi Selatan adalah sebesar 124984 trip per tahun. Hasil tangkapan maksimum lestari (MSY) adalah sebesar 1551.927677 ton per tahun (Gambar 3). Model ini menghasilkan garis lengkung bila $\mathrm{Y} / \mathrm{f}$ secara langsung di plot terhadap upaya, $\mathrm{f}$, namun demikian, apabila $\mathrm{Y} / \mathrm{f}$ di plot dalam bentuk logaritme terhadap upaya, maka akan menghasilkan garis lurus :

$$
\frac{\mathbf{Y}(\mathbf{i})}{\mathbf{f}(\mathbf{i})}=\operatorname{EXP}\left(\mathbf{c}+\mathbf{d}^{*} \mathbf{f}(\mathbf{i})\right)
$$

Gambar 3 menunjukkan bahwa jika faktor di luar penangkapan (effort) diabaikan 
atau dianggap konstan, maka akibat penambahan upaya penangkapan atau jumlah trip penangkapan secara terus menerus, mengakibatkan hasil tangkapan akan mengalami penurunan. Ini berarti bahwa pada upaya atau effort 124984 trip atau melewati upaya penangkapan ini, maka usaha penangkapan akan mengalami kerugian.

MSY dan Fopt Pendekatan Fox

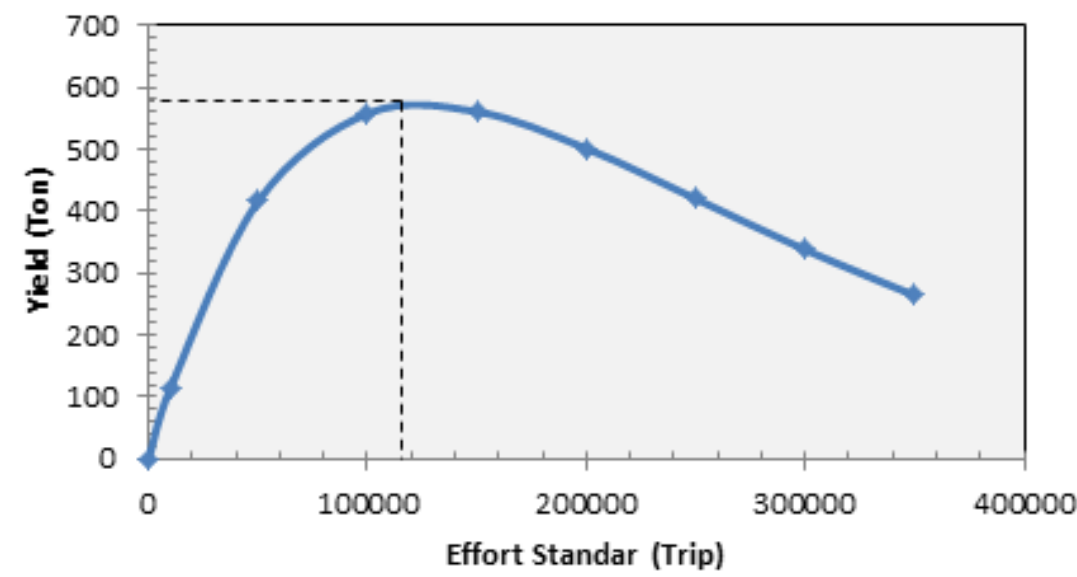

Gambar 3. Kurva MSY berdasarkan pendekatan model Fox Ikan Kerapu di Perairan Selat Makassar Sulawesi Selatan Tahun 1999 - 2007.

Tabel 2. Estimasi Hasil Tangkapan Maksimum Lestari (MSY) dan Effort Optimum (Foptimum) Ikan Kerapu di Perairan Selat Makassar Sulawesi Selatan, Tahun 1999 - 2007 berdasarkan metode Sceafer dan Fox.

\begin{tabular}{crrr}
\hline $\begin{array}{c}\text { Komponen } \\
\text { Penilaian }\end{array}$ & Model Sceafer & Model Fox & Satuan \\
\hline a & 0.008079763 & -4.388687908 & \\
b & $-2.349 \mathrm{E}-08$ & $-8.00102 \mathrm{E}-06$ & \\
MSY & 85992.30745 & 1551.927677 & Ton \\
Fopt & 171984.6149 & 124984 & Trip \\
\hline
\end{tabular}

Jika didasarkan pada data produksi per tahun, kegiatan penangkapan ikan kerapu khususnya ikan kerapu sunu dapat dikatakan belum terjadi overfishing oleh karena hasil tangkapan belum mencapai nilai estimasi MSY dan nilaf effort optimal (Fopt). Namun demikian, perlu dilakukan pengelolaan perikanan yang optimal dengan pendekatan kebijkaan penggunaan alat tangkap selektif agar pemanfaatan ikan kerapu tidak terjadi over fishing dan stok tetap lestari.

Dengan mendasarkan pada kedua pendekatan tersebut di atas, maka dapat diketahui bahwa dengan penambahan setiap jumlah per satuan upaya penangkapan dapat mengakibatkan terjadinya penurunan hasil tangkapan per satuan produksi. Begitu pula sebaliknya, pengurangan atau efisiensi jumlah per satuan upaya penangkapan dapat berdampak pada peningkatan jumlah produksi per satuan produksi. Pada Gambar 4, menunjukkan terjadinya peningkatan jumlah produksi Ikan Kerapu di perairan Selat Makassar dari tahun 1999-2007. Hal ini disebabkan oleh karena adanya pengurangan atau efisiensi jumlah upaya penangkapan per satuan upaya. Hal ini terlihat pada jumlah satuan upaya dari tahun 1999-2007 mengalami penurunan (Gambar 4). 


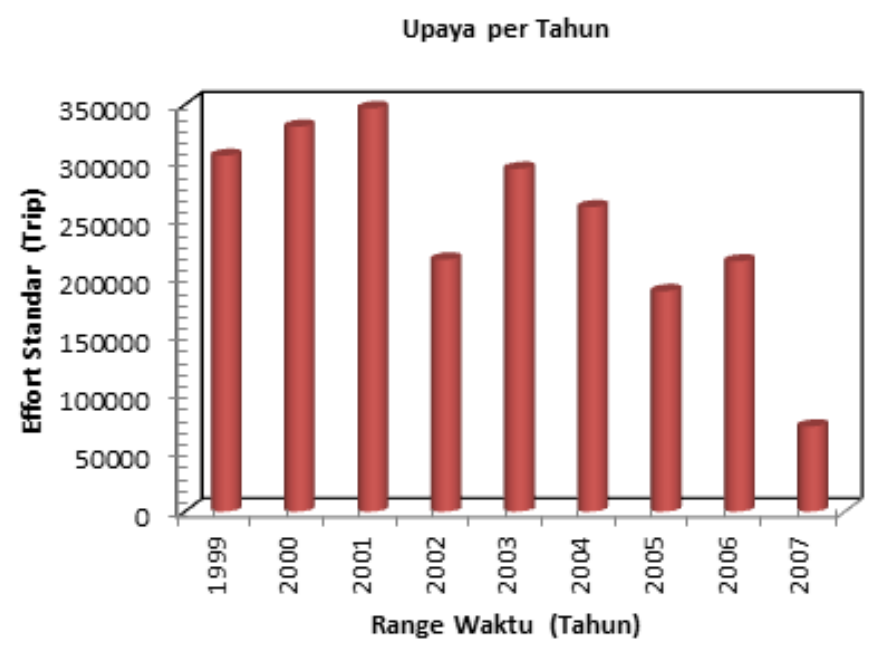

Gambar 5. Upaya penangkapan per tahun Ikan Kerapu di Perairan Selat Makassar Sulawesi Selatan Tahun 1999 - 2007.

\section{PENUTUP}

\subsection{Kesimpulan}

Hasil analisis tangkapan ikan kerapu (grouper) di Perairan Selat Makassar Sulawesi Selatan yang meliputi Kota Makassar, Kabupaten Maros, Kabupaten Pangkajene dan Kepulauan (Pangkep), Kabupaten Barru, Kota Pare-Pare dan Kabupaten Pinrang, belum mengalami over fishing berdasarkan pendekatan model Schaefer, dengan nilai estimasi hasil tangkapan lestari (MSY) yakni sebesar 85992.30745 ton per tahun dengan nilai estimasi Foptimum 171984.6149 trip per tahun.

Berdasarkan pendekatan model Fox, hasil analisis penangkapan ikan kerapu pada perairan Selat Makassar yang meliputi Kota Makassar, Kabupaten Maros, Kabupaten
Pangkajene dan Kepulauan, Kabupaten Barru, Kota Pare-Pare dan Kabupaten Pinrang, belum mengalami over fishing, dengan nilai estimasi hasil tangkapan lestari (MSY) yakni sebesar 1551.927677 ton per tahun dengan nilai estimasi Foptimum 124984 trip per tahun.

\subsection{Saran}

Perlu pengelolaan sumberdaya perikanan ikan karang dalam bentuk intervensi kebijakan khususnya ikan kerapu agar tidak terjadi over fishing. Selain itu diharapkan Dinas Kelautan dan Perikanan dapat membuat data hasil tangkapan dan trip yang lebih akurat agar pengelolaan perikanan khususnya pengelolaan ikan kerapu menjadi lebih baik.

\section{DAFTAR PUSTAKA}

Anonim, 2004, Manajemen Penangkapan Ikan Karang Indonesia WWF Indonesia dan Yayasan ULI Peduli. Edisi 5, Juli-Sept (http://www2.kompas.com/kompas-cetak/0303/05/bahari/ 163616.htm) (serial on-Line).

Cornish, A. \& Kiwi, L.K. 2006. IUCN Red List of Threatened Species Plectropomus leopardus.

Cornish, A. 2007. Epinephelus fuscoguttatus (http://www.iucnredlist.org/search/details.php /44673/all). 2006 IUCN Red List of Threatened Species. (http://www.iucnredlist.org).

Dinas Perikanan Provinsi Jabar, 2008. KLASIFIKASI TEKNIK PENANGKAPAN IKAN http:/hobiikan. blogspot.com/2010/02/klasifikasi-teknik-penangkapan-kan.html (serial on-Line)

Dinas Kelautan dan Perikanan, 1998. Data Produksi Hasil Perikanan Provinsi Sulawesi Selatan. Data Statistik Dinas Kelautan Perikanan Provinsi Sulawesi Selatan Tingkat 1. 
Dinas Kelautan dan Perikanan, 1999. Data Produksi Hasil Perikanan Provinsi Sulawesi Selatan. Data Statistik Dinas Kelautan Perikanan Provinsi Sulawesi Selatan Tingkat 1.

Dinas Kelautan dan Perikanan, 2000. Data Produksi Hasil Perikanan Provinsi Sulawesi Selatan. Data Statistik Dinas Kelautan Perikanan Provinsi Sulawesi Selatan Tingkat 1.

Dinas Kelautan dan Perikanan, 2001. Data Produksi Hasil Perikanan Provinsi Sulawesi Selatan. Data Statistik Dinas Kelautan Perikanan Provinsi Sulawesi Selatan Tingkat 1.

Dinas Kelautan dan Perikanan, 2002. Data Produksi Hasil Perikanan Provinsi Sulawesi Selatan. Data Statistik Dinas Kelautan Perikanan Provinsi Sulawesi Selatan Tingkat 1.

Dinas Kelautan dan Perikanan, 2003. Data Produksi Hasil Perikanan Provinsi Sulawesi Selatan. Data Statistik Dinas Kelautan Perikanan Provinsi Sulawesi Selatan Tingkat 1.

Dinas Kelautan dan Perikanan, 2004. Data Produksi Hasil Perikanan Provinsi Sulawesi Selatan. Data Statistik Dinas Kelautan Perikanan Provinsi Sulawesi Selatan Tingkat 1.

Dinas Kelautan dan Perikanan, 2005. Data Produksi Hasil Perikanan Provinsi Sulawesi Selatan. Data Statistik Dinas Kelautan Perikanan Provinsi Sulawesi Selatan Tingkat 1.

Dinas Kelautan dan Perikanan, 2006. Data Produksi Hasil Perikanan Provinsi Sulawesi Selatan. Data Statistik Dinas Kelautan Perikanan Provinsi Sulawesi Selatan Tingkat 1.

Dinas Kelautan dan Perikanan, 2007. Data Produksi Hasil Perikanan Provinsi Sulawesi Selatan. Data Statistik Dinas Kelautan Perikanan Provinsi Sulawesi Selatan Tingkat 1.

Kompas, 2003. http://www2.kompas.com. Rabu, 5 Maret 2003.

Kekenusa, J, 2007. Pemodelan Hasil Tangkapan dan Evaluasi Model Produksi Surplus Ikan Cakalang yang tertangkap di Perairan sekitar Bitung Provinsi Sulawesi Utara. http://www.adln.lib.unair.ac.id. Diakses tanggal 20 Mei 2009.

Per Sparre dan Siebren C Venema, 1998. Introduction to Tropical Fish Stock Assessment - Part 1: Manual. FAO FISHERIES TECHNICAL PAPER 306/1 Rev. 2 INTERNATIONAL YEAR OF THE OCEAN '98 DANIDA, Food and Agriculture Organization of the United Nations. FAO - FIAT PANIS. Rome

Ranier Froese dan Daniel Pauly. 2007. "Epinephelus tauvina" (http://www.fishbase.org/Summary/SpeciesSummary.cfm?genusname=Epinephelus\&spec iesname=tauvina). FishBase.

Samoilys, M. \& Pollard, D. 2000. Chromileptes altivelis (http://www.iucnredlist.org/search/ details.php/39774/ all). 2006 IUCN Red List of Threatened Species. (http://www.iucnredlist.org).

Setyohadi, D. Tri Djoko Lelono, Dewa Gede Paka Wiadnya. 2004. Dinamika Populasi, Pendekatan Analitik untuk pendugaan dan status perikanan tangkap. Fakultas Perikanan. Universitas Brawijaya. Malang.

Swadaya, 2008. http://hobiikan.blogspot.com. Diakses tanggal 20 mei 2009

Widodo J, Suadi, 2006. Pengelolaan Sumberdaya Perikanan Laut. Gadjah Mada University Press. 